\title{
PERSEPSI GURU TERHADAP PELATIHAN KARYA TULIS ILMIAH DI KABUPATEN SEKADAU
}

\author{
Aunurrahman ${ }^{1}$, Musa $^{2}$, Dada Suhaida ${ }^{3}$, Muhammad Lahir ${ }^{4}$, \\ Agus Dediansyah $^{5}$ \\ ${ }^{1}$ Program Studi Pendidikan Bahasa Inggris IKIP PGRI Pontianak \\ ${ }^{2}$ Program Studi Pendidikan Matematika IKIP PGRI Pontianak \\ ${ }^{3}$ Program Studi Pendidikan PKn IKIP PGRI Pontianak \\ ${ }^{4}$ Program Studi Pendidikan Bahasa Indonesia IKIP PGRI Pontianak \\ ${ }^{5}$ Program Studi Pendidikan Sejarah IKIP PGRI Pontianak \\ 1e-mail: yarrha@gmail.com
}

\begin{abstract}
Abstrak
Penelitian bertujuan untuk mendeskripsikan persepsi guru terhadap pelatihan karya tulis ilmiah (KTI) di Kabupaten Sekadau. Pelatihan KTI diadakan selama 6 hari dari tanggal 22-27 Oktober 2018 yang diikuti 20 guru dari berbagai sekolah yang ada di Kabupaten Sekadau sebagai peserta aktif. Penelitian menggunakan pendekatan kualitatif. Kuesioner terbuka didistribusikan kepada para guru yang mengikuti pelatihan KTI. Respons para guru dianalisis menggunakan analisis tematik. Peserta menunjukkan persepsi bahwa guru memerlukan pelatihan KTI. Hasil analisis terhadap respons kuesioner terbuka menunjukkan bahwa guru telah memiliki pemahaman dasar akan KTI. Guru juga memiliki harapan yang tinggi terhadap pelatihan KTI yaitu untuk membantu mereka menghasilkan KTI yang berkualitas dan dapat dipergunakan sebagai syarat kenaikan pangkat. Guru juga berharap dan memberi saran ada kegiatan tindak lanjut berupa bimbingan intensif untuk guru setelah pelatihan KTI.
\end{abstract}

Kata Kunci: persepsi guru, pelatihan karya tulis ilmiah, respons.

\begin{abstract}
This research aims to describe teachers' perceptions towards scientific writing training. Scientific writing training was conducted for six days from 22-27 October 2018 in Sekadau regency. This research used a qualitative approach. An open-ended questionnaire was distributed to 20 teachers from various schools in Sekadau regency who attended the training. The responsses of the teachers were analyzed using thematic analysis. The teachers' perception is they need this kind of traning of scientific writing.The results of the analysis show that the teachers have a basic understanding of scientific writing. The teachers also have a high expectation towards the training, that is, to help them to construct a good quality of scientific texts, which can be used as a requirement for a promotion. Lastly, the teachers suggest a follow-up activity in the form of intensive guidance for the teachers who have followed the training.
\end{abstract}

Keywords: teachers' perceptions, scientific writing training, responses.

\section{PENDAHULUAN}

Kemampuan menulis bukanlah kemampuan bahasa yang didapatkan secara alamiah. Kemampuan menulis merupakan kemampuan bahasa yang harus dipelajari, karena menulis melibatkan aktivitas yang kompleks (Cheung, 2016). 
Aktivitas menulis yang kompleks memerlukan proses yang tidak sebentar dan rekursif (Emilia, 2005). Hal tersebut membuat kemampuan menulis menjadi kemampuan bahasa yang cukup sulit untuk dikuasai, apalagi kalau menulis secara ilmiah (Aunurrahman, Hamied, dan Emilia, 2017b).

Faktanya adalah kemampuan menulis tidak hanya tentang proses menulisnya yang memerlukan waktu dan rekursif, namun juga dipengaruhi oleh konteks karena menulis juga merupakan aktivitas yang memiliki tujuan sosial, struktur skematis, dan fiturlinguistik yang bervariasi untuk masing-masing tipe tulisan (Emilia dan Tehseem, 2013; Martin, 2014). Dalam konteks akademik, menulis ilmiah memerlukan pengetahuan dasar tentang struktur skematis beserta fiturlinguistik dan etika menulis ilmiah (Aunurrahman dkk., 2017b; Gillett, 2017; Irvin, 2010; Jones, 2011).

Umumnya, menulis karya ilmiah dalam bentuk makalah, jurnal, skripsi, tesis, dan disertasi dipelajari dengan rinci di perguruan tinggi karena menjadi persyaratan kelulusan yang wajib dipenuhi oleh setiap mahasiswa, termasuk mahasiswa yang mengambil program studi di bidang pendidikan (Azhwin, 2016; Darma, Jumaryadi, dan Baharuddin, 2017). Penulisan karya tulis ilmiah yang telah dipelajari oleh mahasiswa tersebut tentu saja akan sangat berguna terutama bagi mahasiswa yang menjadi pegawai negeri sipil (PNS) tenaga pendidikan atau guru, karena tugas guru tidak hanya mendidik, menilai, dan mengevaluasi peserta didik. tapi juga perlu mengembangkan kualitas dirinya sebagai guru yang dikenal dengan pengembangan keprofesian berkelanjutan (Rube'i, Firmansyah, dan Moad, 2019).

Salah satu cara pengembangan keprofesian berkelanjutan (PKB) yang akan menjadi fokus penelitian adalah publikasi karya tulis ilmiah (KTI). Publikasi KTI tentu saja sangat berguna, tidak hanya untuk mengembangkan kualitas diri seorang guru, namun juga memiliki peran besar untuk kenaikan pangkat/golongan yang juga berkaitan langsung dengan kesejahteraan sebagai guru, terutama guru PNS(Sukarno, 2016). Berkaitan dengan hal tersebut, kegiatan berupa pelatihan KTI dilakukan untuk membantu guru-guru di Kabupaten Sekadau untuk menulis karya tulis ilmiah karena walaupun kemampuan ini sudah dipelajari sebelumnya 
di perguruan tinggi, kenyataannya guru masih mengalami kesulitan dalam menulisnya (Sukarno, 2016).

Berdasarkan kegiatan pelatihan yang telah dilakukan, peneliti memfokuskan penelitian pada pertanyaan penelitian, yaitu "Bagaimana persepsi guru-guru terhadap pelatihan karya tulis ilmiah di Kabupaten Sekadau?” Studi yang telah dilakukan sebelumnya oleh Hendrik dan Martahayu (2018) dan Supriyadi (2015) menunjukkan bahwa guru memiliki tingkat pemahaman dan pengetahuan yang rendah akan KTI. Kedua studi tersebut meneliti tentang persepsi guru terhadap KTI di konteks alami tanpa adanya pelatihan KTI. Oleh karenanya, penelitian melihat diperlukannya studi tentang persepsi guru dalam konteks pelatihan KTI di Kabupaten Sekadau. Persepsi guru-guru akan banyak membantu peneliti untuk mempersiapkan pelatihan karya tulis ilmiah yang lebih baik dan berkelanjutan agar guru-guru dapatmenghasilkankaryatulis yang berkualitas.

\section{METODE}

Dalam rangka mencapai tujuan penelitian, yaitu tentang persepsi guru-guru terhadap pelatihan karya tulis ilmiah (KTI) di Kabupaten Sekadau, maka penelitian menggunakan pendekatan kualitatif. Pendekatan kualitatif memungkinkan penulis untuk mengeksplorasi sebuah isu, dalam penelitian yaitu persepsi guru-guru di Kabupaten Sekadau dan mengembangkan sebuah pemahaman yang rinci terhadap isu tersebut (Creswell, 2012). Karena sifatnya yang kualitatif, hasil penelitian tidak dapat digeneralisasi apalagi mewakili persepsi guru di Kabupaten Sekadau secara umum, mengingat tidak semua guru di Kabupaten Sekadau mengikuti kegiatan pelatihan KTI yang diadakan oleh peneliti.

Penelitian melibatkan 20 guru yang telah berpartisipasi aktif di Pelatihan Karya Tulis Ilmiah yang diadakan di Kabupaten Sekadau selama 6 hari dari tanggal 22-27 Oktober 2018. Para partisipan diberikan pengetahuan dasar mengenai struktur karya tulis ilmiah dan cara menulisnya yang termasuk juga penggunaan fitur linguistik dan etika menulis ilmiah. Untuk pelatihan KTI yang dilakukan, penulisan KTI diarahkan kepada penelitian tindakan kelas dan 
penelitian tindakan sekolah yang lebih sering diaplikasikan oleh para guru (Kusumah, 2012; Windayana, 2016).

Pengumpulan data untuk penelitian menggunakan kuesioner. Kuesioner merupakan instrumen penelitian yang dibuat untuk mendapatkan data tertulis seperti pengetahuan, opini, keyakinan, opini, dan persepsi akan suatu isu atau fenomena dari partisipan (Chasteauneuf, 2010; Creswell, 2012). Tipe kuesioner yang digunakan adalah kuesioner terbuka, dimana tidak ada pilihan responss. Hal tersebut memungkinkan partisipan untuk menyediakan respons partisipan yang bervariasi dengan kata-katanya sendiri (Creswell, 2012; Geer, 1988).

Kuesioner terbuka yang didistribusikan kepada partisipan memiliki dua bagian penting. Bagian pertamaberisi profil partisipan yang mengikuti pelatihan KTI yang terdiri dari nama, jenis kelamin, umur, nomor telepon genggam, dan asal sekolah. Perlu diketahui bahwa profil partisipan yaitu nama dan asal sekolah tidak akan ditampilkan sebagai bagian dari kode etik penelitian (Fraenkel, Wallen, dan Hyun, 2011). Hanya data nama anonim dan satuan pendidikan yang diajar yang akan ditampilkan. Bagian kedua adalah pertanyaan terbuka yang harus dijawab oleh para partisipan. Pertanyaan yang perlu dijawab oleh para partisipan bertujuan untuk mengeksplorasi persepsi para partisipan terkait pelatihan KTI yang dimulai dengan judul penelitian, pengetahuan partisipan tentang KTI, dan harapan partisipan dari pelatihan KTI.

Data respons kuesioner yang telah terkumpul dari para partisipan dianalisis menggunakan teknik analisis tematik. Teknik analisis tematik umumnya digunakan untuk menganalisis data kualitatif yang menggunakan pendekatan induktif dalam mengkoding tema-tema yang sering muncul dari data tekstual (Fereday dan Muir-Cochrane, 2008; Guest, MacQueen, dan Namey, 2011; Lancia, 2012; Lapadat, 2010; Miles dan Huberman, 1994) seperti respons yang dapat ditemukan dari kuesioner terbuka yang telah diisi oleh para partisipan.

Ada tiga tema yang telah didapatkan dari analisis tematik terhadap respons kuesioner terbuka. Tiga tema tersebut adalah pemahaman terhadap KTI, harapan, serta saran dan kritik terhadap pelatihan KTI. Sementara, respons partisipan 
terhadap pertanyaan terkait penelitian digunakan untuk mengetahui usaha para partisipan selama pelatihan KTI.

\section{HASIL DAN PEMBAHASAN}

Profil partisipan yang telah mengikuti pelatihan KTI di Kabupaten Sekadau disajikan pada tabel berikut.

Tabel 1 Profil Partisipan Pelatihan KTI di Kabupaten Sekadau

\begin{tabular}{cccccc}
\hline No & Nama & $\begin{array}{c}\text { Jenis } \\
\text { Kelamin }\end{array}$ & $\begin{array}{c}\text { Umur } \\
\text { (Tahun) }\end{array}$ & $\begin{array}{c}\text { Satuan Pendidikan } \\
\text { yang Diajar }\end{array}$ & $\begin{array}{c}\text { Menyebutkan } \\
\text { Judul Penelitian }\end{array}$ \\
\hline 1 & Heru & Laki-laki & 53 & SMP & Iya \\
2 & Anggi & Perempuan & 50 & SD & Iya \\
3 & Ahmad & Laki-laki & 50 & SMP & Tidak \\
4 & Romi & Laki-laki & 46 & SD & Iya \\
5 & Gai & Laki-laki & 51 & SD & Iya \\
6 & Kali & Laki-laki & 56 & SD & Tidak \\
7 & Pati & Laki-laki & 48 & SD & Tidak \\
8 & Migan & Laki-laki & 53 & SD & Iya \\
9 & Ali & Laki-laki & 53 & SD & Iya \\
10 & Jesi & Laki-laki & 45 & SD & Iya \\
11 & Vino & Laki-laki & 50 & SD & Iya \\
12 & Susi & Perempuan & 50 & SMP & Iya \\
13 & Sana & Perempuan & 42 & SMP & Iya \\
14 & Mizan & Laki-laki & 49 & SD & Iya \\
15 & Lilik & Perempuan & 41 & SMP & Iya \\
16 & Susan & Perempuan & 51 & SMP & Iya \\
17 & Laman & Laki-laki & 39 & SD & Tidak \\
18 & Deni & Perempuan & 50 & SD & Iya \\
19 & Liman & Laki-laki & 56 & SD & Tidak \\
20 & Iman & Laki-laki & 49 & SD & Tidak \\
\hline
\end{tabular}

Tabel 1 menunjukkan mayoritas partisipan yang hadir adalah laki-laki, yaitu sebanyak 14 guru. Sementara, partisipan perempuan yang hadir sebanyak 6 guru. Mayoritas partisipan yang hadir merupakan guru yang mengajar SD (sekolah dasar) sebanyak 14 guru. Guru SMP (sekolah menengah pertama) yang hadir sebanyak 6 guru. Dari 20 partisipan yang hadir, 14 partisipan bersedia menyebutkan judul penelitian yang akan ditulis. Sementara, 6 partisipan lainnya tidak menyebutkan judul penelitian yang akan ditulis. Walaupun demikian, bukan artinya para partisipan tidak memiliki topik atau judul penelitian untuk ditulis 
karena pelatihan KTI ini diselenggarakan selama 6 hari, jadi para partisipan tidak sempat atau tidak ingin mengisi judul atau topik penelitiannya pada kuesioner yang telah disediakan.

Kemudian, para partisipan umumnya berada pada rentang usia 40-50 tahun. Bahkan, ada beberapa partisipan yang merupakan kepala sekolah. Sayangnya, penulis tidak memiliki data profil mengenai partisipan yang merupakan kepala sekolah tersebut. Mengetahui hadirnya kepala sekolah, pemberian materi dan pembimbingan tidak hanya mengenai penelitian tindakan kelas (PTK), namun juga penelitian tindakan sekolah (PTS) yang lebih cocok untuk setingkat kepala sekolah (Osnal, 2016; Windayana, 2016).

Apabila PTK difokuskan di lingkungan kelas, maka PTS difokuskan di lingkungan yang lebih luas, yaitu sekolah. Kepala sekolah dapat melakukan penelitian terkait supervisi klinis seperti supervisi terhadap pengajaran guru di kelas dan membantu perencanaan pembelajaran guru-guru. PTS juga dapat dilakukan oleh pengawas sekolah yang penelitian tindakannya bisa difokuskan kepada tugas-tugas manajerial kepala sekolah dan tugas-tugas akademik guru (Windayana, 2016).

Berdasarkan hasil analisis tematik terhadap respons kuesioner yang menggunakan pendekatan induktif dalam menemukan dan mengkoding tematema yang sering muncul, ditemukan satu tema yang mengungkapkan bahwa para partisipan memiliki pemahaman dasar akan KTI. Lilik dan Ahmad, perwakilan dari partisipan, mengungkapkan pemahamannya akan KTI di kuesioner, yaitu:

KTI adalah karya tulis yang memiliki kaidah, struktur, dan sistematika penulisan yang perlu diperhatikan. (Lilik)

Karya tulis hasil dari suatu penelitian yang disajikan/ disampaikan/dilaporkan secara ilmiah. (Ahmad)

Lilik memberikan respons yang jelas bahwa KTI memliki kaidah, struktur, dan sistematika penulisan yang perlu diperhatikan. Responss menunjukkan bahwa para partisipan memiliki pemahaman dasar akan KTI. Untuk dapat menulis KTI, para partisipan harus dapat menguasai struktur skematis teks KTI dan fitur-fitur bahasa yang diperlukan untuk mengkomunikasikan ide secara ilmiah pula (Emilia, 
2009a, 2009b). Pernyataan Ahmad juga menunjukkan pemahaman dasar akan KTI, terutama terkait aspek ilmiah. Hal tersebut relevan dengan etika menulis ilmiah, seperti mengutip ide atau tulisan orang lain yang tentu saja harus dipelajari agar tulisan para partisipan dapat dikatakan ilmiah dan tidak plagiat (Aunurrahman, Hamied, dan Emilia, 2016, 2017a).

Terkait struktur skematis KTI yang diajarkan, Sana dan Romi, perwakilan dari partisipan, mengungkapkan pemahamannya di dalam responsnya terhadap kuesioner terbuka, yaitu:

Karya tulis ilmiah yang ditulis berdasarkan sistematika penelitian tindakan kelas. (Sana)

Laporan penelitian tentang hasil pembelajaran dan perbaikan/melatih guru untuk menuliskan masalah yang ditemukan dalam kegiatan belajar mengajar di sekolah dan mencari jalan keluar untuk menyelesaikannya. (Romi)

Respons Sana menunjukkan pemahamannya tentang KTI berhubungan dengan sistematika PTK. Sistematika atau struktur skematis penulisan KTI yang diajarkan dimulai dari pendahuluan, kajian pustaka, metodologi penelitian, hasil dan pembahasan, simpulan dan saran, dan daftar pustaka (Emilia, 2009b). Sistematika juga umumnya ditemukan dalam penulisan artikel jurnal, skripsi, dan disertasi walaupun kata-kata yang digunakan bisa saja berbeda, tergantung konteks sosialnya (Emilia, 2009a). Sementara, PTK merupakan salah satu desain yang dapat digunakan oleh peneliti untuk mencapai tujuan penelitiannya (Malik dan Hamied, 2014). Deskripsi PTK diuraikan dengan baik oleh Romi yang ternyata sesuai dengan tujuan dari desain penelitian PTK tersebut (Burns, Westmacott, dan Ferrer, 2016). Terkait struktur skematis penulisan KTI yang diajarkan dengan jurnal atau skripsi, bagian yang akan nampak berbeda hanyalah konten pada bagian metodologi penelitian dan pembahasan data penelitian. Hal tersebut tidak akan memengaruhi sistematika penulisan ilmiah pada umumnya.

Romi dan Mizan, perwakilan dari partisipan, mengungkapkan pemahamannya lebih jauh mengenai PTK dan PTS. 
Melatih guru untuk menuliskan masalah yang ditemukan dalam kegiatan belajar mengajar di sekolah. (Romi)

Sebuah penelitian tentang permasalahan di sekolah dan solusi. (Mizan)

Respons Romi menunjukkan pemahaman yang cukup dalam mengenai PTK terkait dengan fungsinya yaitu untuk menuliskan masalah yang ditemukan di dalam kelas. Tentu saja, fungsi PTK lebih dari menemukan dan menulis masalah. PTK adalah desain penelitian yang dapat digunakan untuk mengatasi masalah yang ditemukan atau meningkatkan kinerja suatu organisasi, termasuk kelas ataupun sekolah (Burns dkk., 2016; Creswell, 2012; Windayana, 2016). Terkait PTS, Mizan memberikan respons yang cukup jelas dan linear dengan teori bahwa PTS merupakan desain penelitian yang menemukan permasalahan di konteks yang lebih luas dari kelas, yaitu sekolah dan memberikan solusi terhadap masalah tersebut.

Respons tersebut menunjukkan bahwa partisipan memiliki pemahaman akan KTI. KTI memiliki sistematika atau struktur skematis, kaidah atau fitur bahasa, dan etika dalam mengkomunikasikan ide atau tulisan agar menjadi ilmiah, mengingat KTI merupakan teks yang lumrah digunakan di konteks akademik. Selama 6 hari, partisipan jelas berkutat dengan materi yang telah disebutkan di atas. Selanjutnya, peneliti akan mengungkapkan harapan para partisipan dari pelatihan KTI yang telah diadakan di Kabupaten Sekadau. Harapan tersebut bisa menjadi motivasi ataupun tujuan dari kehadiran partisipan di pelatihan KTI tersebut.

Hasil analisis respons terhadap kuesioner menunjukkan dua harapan partisipan terhadap pelatihan KTI. Diantaranya dikemukakan oleh Susi dan Romi.

Harapan saya setelah ini dapat membuat KTI yang berkualitas.(Susi)

Dapat membuat sebuah KTI dalam rangka memenuhi syarat untuk kenaikan pangkat. (Romi)

Dapat dilihat bahwa Susi memiliki harapan yang besar dari pelatihan KTI yang telah diadakan di Kabupaten Sekadau, yaitu menghasilkan KTI yang berkualitas. Lebih jauh, Romi menyebutkan dengan gamblang bahwa harapannya mengikuti pelatihan KTI adalah untuk dapat membuat sebuah KTI yang dapat 
digunakan untuk memenuhi persyaratan kenaikan pangkat. Respons Romi menunjukkan kepada peneliti bahwa KTI menjadi bagian yang penting bagi para guru terutama guru PNS, karena publikasi KTI merupakan salah satu cara pengembangan keprofesian berkelanjutan (PKB). Publikasi KTI tentu saja sangat berguna, tidak hanya untuk mengembangkan kualitas diri seorang guru, namun juga memiliki peran besar untuk kenaikan pangkat/golongan yang juga berkaitan langsung dengan kesejahteraan sebagai guru terutama guru PNS (Sukarno, 2016).

Tentu saja, untuk meraih KTI yang berkualitas tidaklah mudah. Walaupun KTI sudah dipelajari sebelumnya di perguruan tinggi, kenyataannya guru-guru masih mengalami kesulitan dalam menulisnya (Sukarno, 2016). Belum lagi, menulis merupakan aktivitas yang kompleks dan rekursif (Emilia, 2005). Oleh karenanya, pelatihan KTI diadakan, yaitu untuk memberikan bimbingan secara eksplisit kepada guru-guru untuk menulis KTI yang dapat dipergunakan untuk pengajuan pangkat. Bimbingan eksplisit dapat diartikan tidak hanya memberi materi ajar terkait KTI, tetapi juga menunjukkan bagaimana menulis KTI dan memberikan umpan balik mengenai teks KTI yang ditulis oleh guru-guru (Aunurrahman dkk., 2017a; Cheung, 2016).

Beberapa partisipan juga memberikan saran dan kritik terkait pelaksanaan pelatihan KTI selama 6 hari tersebut. Diantaranya dikemukakan oleh Liman dan Laman.

Waktunya cukup memuaskan. (Liman)

Semoga kegiatan ini bisa berlanjut. (Liman)

Kelemahan dengan waktu pertemuan yang kurang banyak. (Laman)

Sebaiknya disiapkan file terbimbing. (Laman)

Respons Liman dan Laman yang pertama fokus pada waktu. Liman mengemukakan bahwa waktu pelatihan yang dilakukan selama 6 hari cukup memuaskan. Lain halnya dengan Laman yang mengemukakan bahwa waktu 6 hari tersebut kurang mencukupi. Kedua respons menunjukkan bahwa partisipan memiliki pemahaman dan kemampuan yang bervariasi dalam menulis KTI setelah mengikuti pelatihan KTI tersebut. Sayangnya, penelitian tidak fokus pada produk KTI yang telah dihasilkan selama pelatihan KTI. Kedepannya, pelatihan KTI 
harus bisa mengajar para partisipan dengan rentang waktu yang sama (6 hari) secara efektif agar pemahaman dan kemampuan yang didapatkan oleh para partisipan bisa relatif sama.

Liman juga mengomentari bahwa kegiatan pelatihan KTI memerlukan tindak lanjut agar partisipan bisa menyelesaikan tulisan dengan baik yang dibimbing dosen meskipun pelatihan KTI telah usai. Kedepannya, pelatihan KTI harus mempersiapkan kegiatan tindak lanjut untuk guru-guru yang telah mengikuti pelatihan KTI agar dapat menghasilkan teks KTI yang berkualitas. Laman mengomentari terkait perlunya berkas terbimbing. Peneliti memahami bahwa berkas terbimbing berarti pelatihan KTI perlu mempersiapkan contoh KTI yang bisa dipakai agar mempermudah para partisipan dalam menulis draf KTI.

Respons guru-guru tersebut menunjukkan bahwa partisipan memiliki pemahaman dasar akan KTI. Lebih jelasnya, hal tersebut ditunjukkan oleh respons yang diberikan oleh Lilik, Ahmad, Sana, Romi, Mizan, dan Susi terkait pemahaman partisipan akan sistematika penulisan KTI, desain PTK, dan harapan partisipan terhadap pelatihan KTI. Saran dan kritik yang diberikan oleh Liman dan Laman juga menunjukkan bahwa partisipan memerlukan pelatihan KTI. Tentu saja, saran dan kritik tersebut jelas dapat membantu peneliti untuk mempersiapkan pelatihan KTI yang lebih baik dan berkelanjutan di kemudian hari.

Terkait penelitian yang telah dilakukan sebelumnya, studi Hendrik dan Martahayu (2018) menunjukkan bahwa hanya 28\% partisipan guru saja yang dapat dikatakan paham. Penelitian lainnya, yaitu Supriyadi (2015) juga menunjukkan bahwa guru memiliki tingkat pemahaman yang rendah terhadap KTI. Perlu diketahui bahwa dua hasil penelitian tersebut, dilakukan untuk mengetahui persepsi guru di konteks alami tanpa adanya pelatihan KTI yang diadakan untuk guru. Secara tidak langsung, respons guru dan hasil penelitian sebelumnya menunjukkan bahwa pelatihan KTI diperlukan oleh guru untuk membantu menulis KTI yang berkualitas.

Oleh karenanya, penelitian yang dilakukan menyimpulkan bahwa persepsi guru memerlukan pelatihan KTI. Hal tersebut juga didukung oleh partisipan yang 
telah menyebutkan judul penelitian yang akan ataupun sedang ditulis di kuesioner terbuka yang telah didistribusikan. Para partisipan juga memiliki motivasi yang jelas, yaitu untuk dapat menulis KTI yang berkualitas dan dapat digunakan untuk memenuhi persyaratan kenaikan pangkat terutama bagi guru PNS.

\section{SIMPULAN}

Penelitian dilakukan untuk menemukan persepsi guru terhadap pelatihan KTI yang diadakan di Kabupaten Sekadau. Hasil analisis respons terhadap kuesioner terbuka yang telah didistribusikan menunjukkan bahwa 20 guru yang berpartisipasi membutuhkan pelatihan KTI seperti yang telah dilakukan di Kabupaten Sekadau, karena 20 guru tersebut telah memiliki pemahaman dasar tentang KTI. 20 guru peserta aktif dalam pelatihan KTI di Kabupaten Sekadau juga berharap pelatihan KTI dilakukan secara berkelanjutan dengan bimbingan yang intensif, karena guru ingin dapat menulisKTI dengan baik dan dapat menghasilkan KTI yang berkualitas yang dapat digunakan sebagai salah satu syarat untuk kenaikan pangkat.

Kelemahan penelitian yang menggunakan pendekatan kualitatif dalam pengumpulan data yaitu hasil penelitian tidak dapat digeneralisasikan ataupun mewakili persepsi guru di konteks Kabupaten Sekadau, apalagi di konteks Kalimantan, Indonesia. Peneliti yang telah melakukan analisis tematik tidak mengkuantifikasi respons guru untuk dapat menghasilkan kesimpulan yang lebih signifikan. Walaupun demikian, hasil penelitian bisa menjadi sarana bagi peneliti lainnya untuk menyediakan pelatihan KTI yang lebih baik dan berkelanjutan di kemudian hari.

\section{DAFTAR PUSTAKA}

Aunurrahman, Hamied, F. A., \& Emilia, E. 2016. Facilitating Character Building through an Academic Writing Practice. Arab World English Journal, 7(3): $146-160$.

Aunurrahman, Hamied, F. A., \& Emilia, E. 2017a. A Joint Construction Practice in an Academic Writing Course in an Indonesian University Context. Celt (A Journal of Culture, English Language Teaching \& Literature), 17(1): 27-44. 
Aunurrahman, Hamied, F. A., \& Emilia, E. 2017b. Exploring the Tertiary EFL Students' Academic Writing Competencies. Indonesian Journal of Applied Linguistics, 7(1): 72-79.

Azhwin, F. 2016. Mahasiswa Harus Bisa Menulis Karya Ilmiah. Diakses 15 Februari 2019, dari Kompasiana.com website: https://www.kompasiana.com/farhanazhwin/57c536e1a3afbd5445b33ed9/m ahasiswa-harus-bisa-menulis-karya-ilmiah

Burns, A., Westmacott, A., \& Ferrer, A. H. 2016. Initiating an Action Research Programme for University EFL Teachers: Early Experiences and Responses. Iranian Journal of Language Teaching Research, 4(3): 55-73.

Chasteauneuf, C. 2010. Questionnaires. Dalam A. J. Mills, G. Eurepos, \& E. Wiebe (Ed.), Encyclopedia of Case Study Research (Vol. 1, hlm. 768-770). Thousand Oaks California, US: SAGE Publications, Inc.

Cheung, Y. L. 2016. Teaching Writing. Dalam W. A. Renandya \& H. P. Widodo (Ed.), English Language Teaching Today (Vol. 5, hlm. 179-194).

Creswell, J. W. 2012. Educational Research: Planning, conducting, and Evaluating Quantitative And Qualitative Research (4 ed.). Boston: Pearson.

Darma, Y., Jumaryadi, A., \& Baharuddin (Ed.). 2017. Pedoman operasional Akademik, Kemahasiswaan, dan Penulisan Skripsi. Pontianak: IKIP-PGRI Pontianak.

Emilia, E. 2005. A Critical Genre-Based Approach to Teaching Academic Writing in a Tertiary EFL Context in Indonesia (Unpublished Dissertation, The University of Melbourne). Diambil dari https://minervaaccess.unimelb.edu.au/handle/11343/39548

Emilia, E. 2009a. Menulis Tesis dan Disertasi. Diambil dari http://alifviaarviningrum.students-blog.undip.ac.id/files/2010/10/Tesis-danDisertasi-9-Rev-Sept08.pdf

Emilia, E. 2009b. Menulis Karya Tulis Ilmiah. Dipresentasikan pada Pelatihan Guru-Guru SMP, Bandung, Indonesia.

Emilia, E., \& Tehseem, T. 2013. A Synthesis of Approaches to Teaching Writing: A Case Study in an Australian Primary School. Pakistan Journal of Social Sciences, 33(1): 121-135.

Fereday, J., \& Muir-Cochrane, E. 2008. Demonstrating Rigor Using Thematic Analysis: A Hybrid Approach of Inductive and Deductive Coding and Theme Development. International journal of qualitative methods, 5(1): 80-92.

Fraenkel, J. R., Wallen, N. E., \& Hyun, H. H. 2011. How to Design and Evaluate Research in Education (8 ed.). New York: McGraw-Hill Humanities/Social Sciences/Languages.

Geer, J. G. 1988. What Do Open-Ended Questions Measure? Public Opinion Quarterly, 52(3): 365.

Gillett, A. 2017. Features of Academic Writing. Diambil 7 April 2017, dari Using English for academic purposes: A guide for students in higher education website: http://www.uefap.com/writing/feature/featfram.htm

Guest, G., MacQueen, K. M., \& Namey, E. E. 2011. Applied Thematic Analysis. Thousand Oaks, Calif.: Sage. 
Hendrik, M., \& Martahayu, V. 2018. Pemahaman dan Partisipasi Guru Sekolah Dasar dalam Menulis Karya Ilmiah. Society, 6(1): 30-41.

Irvin, L. L. 2010. What is "Academic" Writing? Dalam Charles Lowe \& P. Zemliansky, Writing spaces: Readings on writing (Vol. 1, hlm. 3-17). West Lafayette, IN: Parlor Press.

Jones, L. 2011. Academic integrity \& academic dishonesty: A Handbook about Cheating \& Plagiarism (Revised \& Expanded Edition). Diambil dari https://www.fit.edu/current/documents/plagiarism.pdf.

Kusumah, W. 2012. Pentingnya penelitian tindakan kelas (PTK) bagi guru. Diambil 18 Februari 2019, dari KOMPASIANA website: https://www.kompasiana.com/wijayalabs/55123f84a33311f456ba823e/penti ngnya-penelitian-tindakan-kelas-ptk-bagi-guru.

Lancia, F. 2012. T-LAB Pathways to Thematic Analysis. Diambil dari http://mytlab.com/tpathways.pdf.

Lapadat, J. C. 2010. Thematic Analysis. Dalam A. J. Mills, G. Eurepos, \& E. Wiebe (Ed.), Encyclopedia of Case Study Research (Vol. 1, hlm. 495-499). Thousand Oaks California, US: SAGE Publications, Inc.

Malik, R. S., \& Hamied, F. A. 2014. Research methods: A guide for first time researchers. Bandung, Indonesia: UPI Press.

Martin, J. R. 2014. Evolving Systemic Functional Linguistics: Beyond the Clause. Functional Linguistics, 1(1): 3.

Miles, M. B., \& Huberman, A. M. 1994. Qualitative Data Analysis: An Expanded Sourcebook (2 ed.). California, US: SAGE Publications, Inc.

Osnal. 2016. Meningkatkan Kualitas Pembelajaran Guru Kelas 6 melalui Supervisi Kelas Bersahabat di Gugus I Kecamatan Sumbermalang Kabupaten Situbondo Tahun Pelajaran 2015/2016. Pancaran Pendidikan, 5(1): 133-146.

Rube'i, M. A., Firmansyah, S., \& Moad, M. 2019. Pelatihan Penulisan Artikel Ilmiah pada Guru-Guru Sekolah Dasar Kecamatan Sungai Raya Kabupaten Kubu Raya. GERVASI: Jurnal Pengabdian Kepada Masyarakat, 2(2): 112123.

Sukarno, S. 2016. Kendala dan Upaya Pengembangan Keprofesian Guru Sekolah Dasar melalui Kegiatan Penulisan Karya Ilmiah. Prosiding Seminar Nasional Inovasi Pendidikan, 601-610.

Supriyadi, H. 2015. Persepsi Guru SMP, SMA, dan SMK di Kabupaten Ogan Komering Ilir terhadap Penulisan Karya Ilmiah. Jurnal Logat, 2(2): 139148.

Windayana, H. 2016. Penelitian Tindakan Sekolah. EDUHUMANIORA: Jurnal Pendidikan Dasar, 4(1). 